\title{
Effects of Veronica Officinalis Extract in the Kidney of Rats with Induced Sepsis*
}

Eduardo Henrique Herbster Gouveia1, Rubens Fernando Gonçalves Ribeiro Júnior ${ }^{2}$,
Marcus Vinicius Henriques Brito ${ }^{3}$, Edson Yuzur Yasojima ${ }^{3}$ Andressa Miléo Ferraioli Silva ${ }^{4}$, Andrew Moraes Monteiro ${ }^{4}$, Ivone Aline da Silva Rodrigues ${ }^{4}$, Lucca Oliveira Gonçalves ${ }^{4}$, Luiz Renato Oliveira Lopes ${ }^{5}$

\section{Abstract}

Purpose: To evaluate the effects of Veronica officinalis extract as a anti-inflammatory substance on the kidney function of rats subjected to cecal ligation and puncture, describing histopathological and biochemical findings.

Methods: Twenty rats (Rattus norvegicus) were distributed into four groups ( $\mathrm{N}=5$ ): Sham group (GS), normal standard animals; Sepsis group (GSep), submitted a cecal ligation and puncture (CLP); Veronica group $(\mathrm{GV})$, administered only Veronica officinalis extract once daily by gavage from the first day until the seventh day, without sepsis induction; Sepsis-Veronica group (GSep-V), administered Veronica officinalis extract once daily by gavage from the first day of CLP until the seventh day procedure. After the euthanasia, blood was collected for assessment of kidney biochemical and histological analysis were performed.

Results: The statistical analysis showed that there was statistically significant in serum levels of creatinine between GS and GSep ( $p=0.0029$ ); and GSep and GSep-V ( $p=0.0184)$. In addition, there was statistically significant of histopathological parameters observed between GS and GSep ( $p=0.0001)$; GSep and GV ( $p=0.0415)$; also between GSep and GSep-V $(p=0.0003)$.

Conclusion: Veronica officinalis extract promoted a significant antiinflammatory effect on kidney function and reduction of tissue damage in rats with sepsis.
1 Graduate Medical Student, UEPA, Belem-PA, Brazil.

2 Fellow Master Degree, Postgraduate Program in Surgery and Experimental Research (CIPE), State University of Para (UEPA), Brazil.

3 PhD, Full Professor, Medical School, State University of Para (UEPA), Brazil.

4 Graduate Medical Student, UEPA, Belem-PA, Brazil.

5 Graduate Medical Student, Federal University of Para (UFPA), Belem-PA, Brazil.

*: Research performed at the Laboratory of Experimental Surgery, Professional Master's Program in Surgery and Experimental Research, Para State University (UEPA), Belem, PA, Brazil

Contact information:

Rubens Fernando Gonçalves Ribeiro Júnior.

Address: Avenida Marquês de Herval, 1823. Pedreira. 66087-320 Belém, PA Brasil.

ほ rubensfernandojr@gmail.com

Keywords

Medicinal Plants; Veronica

officinalis; Sepsis;

Inflammation. 


\section{Introduction}

Historically, sepsis is known as a condition in which their identification and diagnosis are difficult and is reported since the beginning of time, being described by more than 2000 years, although the clinical definitions are recent [1]. Furthermore, sepsis is a syndrome resulting from the immune response initiated by an infectious process characterized by hemodynamic and metabolic changes that can lead to septic shock, multiple organ dysfunction and death [2].

Once initiated inflammatory response, cytokines activate several mechanisms such as inflammatory cell recruitment, activation of endothelial cells, vasodilatation, increased capillary permeability, microcirculatory thrombosis, increased production of free radicals, exacerbation of apoptosis and compromised mitochondrial function. All these factors can contribute to reduction in supply or consumption of oxygen, with consequent genesis or worsening organ dysfunction [3].

Between the organs most affected by sepsis, kidney stand out because septic shock causes acute kidney injury $(\mathrm{AKI})$, through modulation of renal inflammation by specific components of the inflammatory cascade induced sepsis, once apoptosis of cells tubular epithelial kidney can be quite significant in sepsis $[4,5]$.

A plant traditionally used to treat lung diseases is the Common Speedwell (Veronica officinalis), a member of the Plantaginaceae Family. In Europe, Veronica officinalis $L$. is a wide spread species found growing a long forest edges, in under wood and meadows up to subalpine altitudes. Especially in the $16^{\text {th }}$ and $17^{\text {th }}$ centuries, Veronica officinalis was recommended for stomach and intestinal diseases, renal lithiasis, colic and pulmonary diseases. In Romanian folk medicine, was used for kidney diseases, cough, and catarrh, and was known for its wound healing properties and its indication in lung diseases [6].
Many drugs have been discovered from plant extracts enshrined in popular scenario of the Amazon region. Among these herbs, there is the popular wisdom "Pau de Veronica" (Veronica officinalis), whose tea of all plant parts are used for inflammation in general, liver disease, bronchitis, pneumonia and influenza [7].

Thus, the aim of this study is to evaluate whether serum urea and creatinine levels and the histopathological parameters are influenced by Veronica officinalis extract in rats induced by sepsis.

\section{Methods}

Before the start of the project, it was approved by the Ethics Committee in the Use of Animals of State University of Pará (UEPA), protocol 01/14. Twenty adults males Wistar rats (Rattus norvegicus) were used, weighing between 200-250g, provided from the Animal Colony of the Experimental Surgery Laboratory of UEPA, kept in a controlled environment, with food and water ad libitum. The animals were randomized distributed into four groups, with eight animals each:

- Sham Group (GS): The animals were used as normal standard for biochemical and histological analysis; the animals underwent the same surgical techniques, but without the performance of CLP;

- Sepsis Group (GSep): Animals were only realized the cecal ligation and puncture (CLP) [8];

- Veronica Group (GV): Administered Veronica officinalis extract $(10 \mathrm{ml} / \mathrm{kg} /$ day) once daily by gavage for seven days [9], without the performance of cecal ligation and puncture (CLP);

- Sepsis-Veronica Group (GSep-V): Administered Veronica officinalis extract $(10 \mathrm{ml} / \mathrm{kg} /$ day $)$ once daily by gavage from the first until the seventh day of the CLP.

The animals were anesthetized with ketamine hydrochloride $(100 \mathrm{mg} / \mathrm{Kg}$ ) and xylazine hydrochloride 
(10 mg/Kg), intraperitoneally. After was performed the epilation and antisepsis of the abdominal region. Subsequently, was performed a laparotomy of three centimeter.

\section{Sepsis induction}

Surgical procedures followed the same pattern described by Botelho et al. [8] that consist in opening the abdominal cavity, locate, expose and isolate the cecum, leaving the rest of the small and large intestine into the peritoneal cavity, taking care not to violate or damage the mesenteric vessels. To induce a high-grade sepsis, $75 \%$ of cecum was ligated with silk 4-0 just after the ileocecal valve. Cecal stump was transfixed by a single throughand-through puncture with a $21 \mathrm{G}$ needle. After the surgical procedure, was administered pre-heated saline $(5 \mathrm{ml} / 100 \mathrm{~g})$ by subcutaneously and dipirona $30 \mathrm{mg} / \mathrm{kg}$ for analgesia.

\section{Plant Extract}

The extract is composed of the herb Veronica officinalis $L$.; the plant material was obtained and the extract was prepared by BioTae ${ }^{\circledR}$ (Sao Paulo/Brazil). The plant material was harvested and dried and specialists of BioTae ${ }^{\circledR}$ confirmed botanical identity through macroscopic and analytical examination. This was followed by a maceration, swirling and boiling process (30min) using a 1/10 dilution of dried plant material and ethanol (50\%).

\section{Laboratory and histopathological analysis}

Performed euthanasia of animals was collect the kidney of the animal, that were stored in $10 \%$ bu- ffered formaldehyde and used for histopathological analysis by means of hematoxylin and eosin.

Kidney function was verified by measuring the serum levels of urea and creatinine. The verification was performed using $3 \mathrm{~mL}$ of plasma analysis, which was prepared by centrifugation at 2500rpm for 15 minutes. The collection was performed immediately after the euthanasia of the animal by inferior vena cava puncture.

\section{Statistical analysis}

Data were reported as means $\pm S D$. Biochemical parameters analysis was compared by the ANOVA test, followed by Tukey test between the groups and histopathological examination by Kruskal-Wallis test, followed by Student-Newman-Keuls test for confirmation of statistical significance, adopting a $5 \%$ significance level to reject the nullity hypothesis. Bioestat $5.3^{\circledR}$ was used for statistical analysis.

\section{Results}

During the research, no animal died after surgical procedure. There were no other complications like dehiscence, fistulae or infection.

The analysis of kidney biochemical parameters (Table 1) shows that was significant statistical difference $(p<0.05)$ in serum levels of creatinine between Sham and Sepsis group ( $p=0.0029)$, also between GSep and GSep-V ( $p=0.0184)$. There was no significant statistical difference on serum levels of urea between groups when compared each other (data no showed).

Table 1. Results of effect of Veronica officinalis extract on kidney biochemical parameters of Wistar rats.

\begin{tabular}{|l|c|c|c|c|c|}
\hline Parámetros Bioquímicos Séricos & GS & GSep & GV & GSep-V & p-valor* \\
\hline Ureia $(\mathrm{mg} / \mathrm{dL})$ & $36 \pm 9.46$ & $39 \pm 10.05$ & $37.4 \pm 5.13$ & $41.2 \pm 6.91$ & 0.7732 \\
\hline Creatinina $(\mathrm{mg} / \mathrm{dL})$ & $0.3 \pm 0.07$ & $0.61 \pm 0.05^{\mathrm{a}}$ & $0.2 \pm 0.0$ & $0.24 \pm 0.09^{\mathrm{b}}$ & $\mathrm{a}^{\mathrm{a}} 0.0029$ \\
\hline
\end{tabular}

ANOVA test. Data are reported as means \pm SD. ${ }^{a}: p<0.05$ in relation to GS; $b: p<0.05$ compared to GSep 
Histopathological examination of the kidney showed inflammatory response in all animals at different levels, with presence of interstitial pyelonephritis, vascular congestion and inflammatory infiltrate, mainly consisting of polymorphonuclear, parenchymal edema, hyaline and hematic casts, but without changing the architecture of the organ. It was also observed tubular and glomerular necrosis.

The histopathological analysis was ranked scores: 0 (absent), 1 (mild), 2 (moderate) and 3 (severe). The variables were compared between groups by the average of the scores (Table 2).

Table 2. Scores of histopathological parameters evaluated between groups.

\begin{tabular}{|l|c|c|c|c|}
\hline \multicolumn{1}{|c|}{ Type of lesion } & GS & GSep & GV & GSep-V \\
\hline Interstitial pyelonephritis & 0.4 & 2.0 & 1.0 & 0.6 \\
\hline Vascular congestion & 0.4 & 1.8 & 1.8 & 0.8 \\
\hline $\begin{array}{l}\text { Polymorphonuclear } \\
\text { infiltrate }\end{array}$ & 0.4 & 1.6 & 1.2 & 0.4 \\
\hline Parenchymal edema & 0.8 & 1.8 & 1.2 & 1.2 \\
\hline Hyaline casts & 0.4 & 1.6 & 0.6 & 0.2 \\
\hline Hematic casts & 0.4 & 1.2 & 0.6 & 0.2 \\
\hline Tubular necrosis & 0.4 & 1.4 & 0.4 & 0.4 \\
\hline Glomerular necrosis & 0.4 & 1.4 & 0.4 & 0.4 \\
\hline General mean & 0.45 & 1.6 & 0.9 & 0.52 \\
\hline
\end{tabular}

There was statistically significant difference of histopathological parameters observed between GS and GSep ( $p=0.0001)$, GSep and GV ( $p=0.0415)$, also between GSep and GSep-V ( $p=0.0003)$ (Figure 1).

Parenchymal edema and infiltration of polymorphonuclear were the most inflammatory parameters observed in all groups during histopathological analysis (Figure 2). Moreover, death from renal tissue was quite evident for tubular necrosis and glomerular.

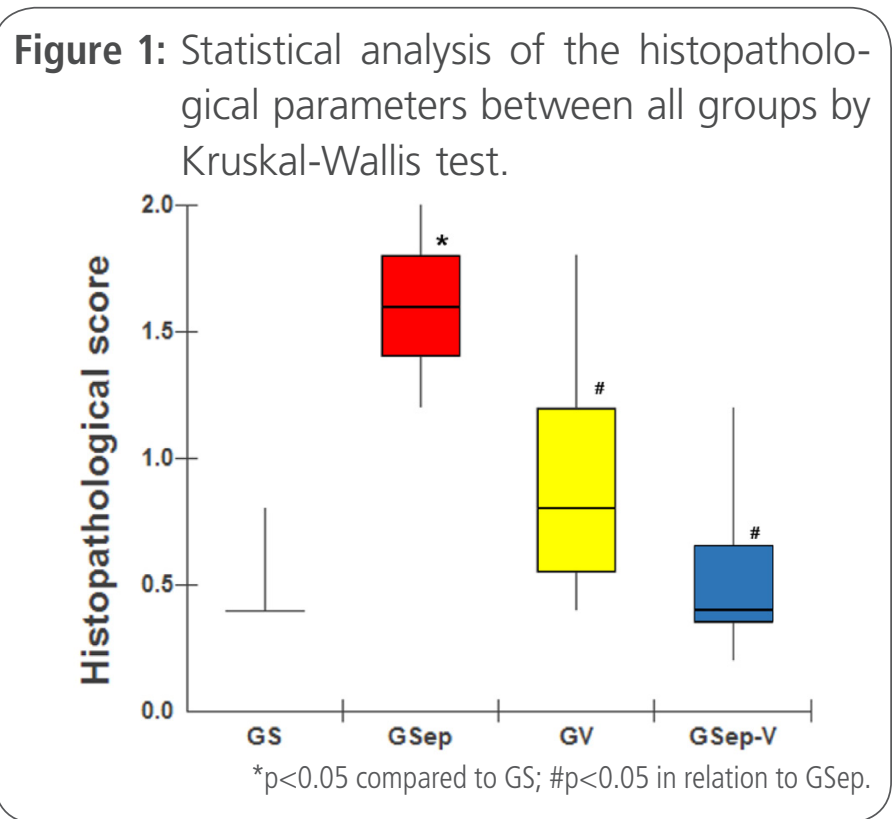

Figure 2: Photomicrograph of stained kidney with hematoxylin-eosin (40x). A: GS; B: GV; C: GSep: arrow indicating nephron with inflammatory infiltrate; D: GSep-V: arrow showing parenchymal edema.
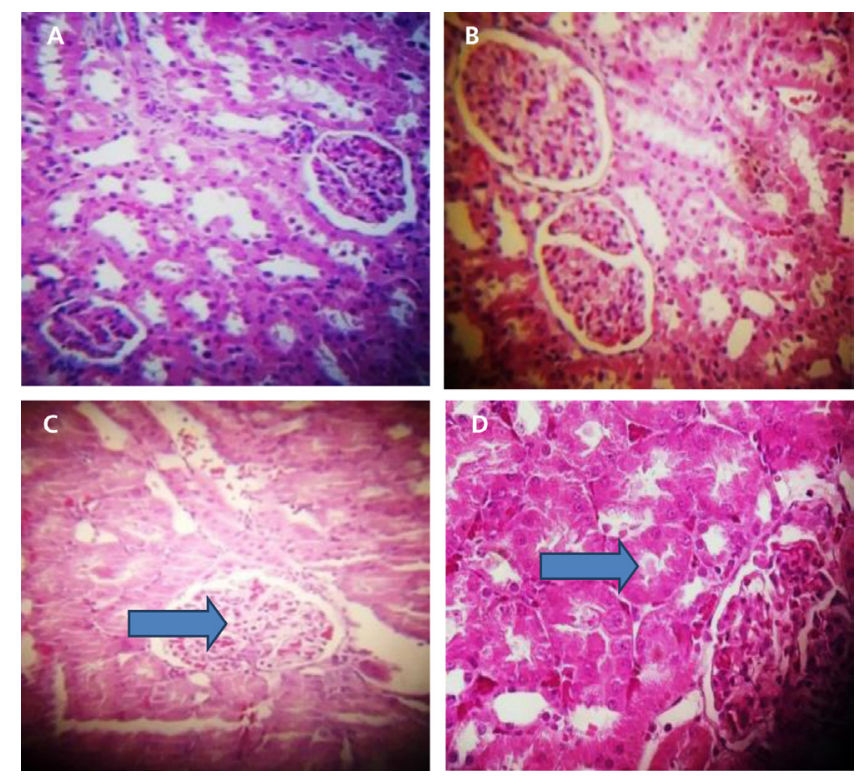

\section{Discussion}

Sepsis is a syndrome resulting from the immune response initiated by an infectious process characterized by hemodynamic and metabolic changes that can lead to septic shock, multiple organ dysfunction and death [2] that presents criteria and definitions 
divided into groups: sepsis, severe sepsis and septic shock [10, 11, 12].

In the present study we used a model of high reproducibility sepsis induction, easy to perform and inexpensive to use. It is different from other models, an infection not by a specific agent, but with the presence of different types and species of microorganisms in the intestinal tract of the animal. There were methodological careful to perform perforations to guarantee the pathogenicity, but the less time not induce severe sepsis that preclude the time of the animal's survival to euthanasia.

The sudden reduction in glomerular filtration determines the diagnosis of acute kidney injury (AKI) is important to note that the first diagnostic test of renal function loss is clinically evidenced by the increase in serum creatinine levels, this criterion inaccurate and late, with proven such changes found in this study [13, 14].

There are several standardizations for the diagnosis of acute kidney injury, including the ADQI group (Acute Dialysis Quality) proposed the severity rating of AKI, the RISK [15].

Subsequently, the AKIN (Acute Kidney Injury Network) group, proposed the modification of the classification and defined AKI as increased serum creatinine greater than or equal to $0.3 \mathrm{mg} / \mathrm{dL}$ or percentage increase equal to or greater than 1.5 times the baseline obtained in the last 48 hours, adding the criterion reduced urine flow as a marker function. It is worth noting that these diagnostic organizations are the most accepted actually [16, 17].

Similar to this research [17], this study demonstrates an increased urea value in the sepsis group was not statistically significant, in addition, there was significant reduction in creatinine clearance between GS and GSep, also between GSep and GSep- $V$, confirming the occurrence of renal damage non oliguric induced sepsis. To confirm renal injury sepsis group was presented the corresponding histological image to the body, which presented quite necrosis and inflammation.
Unlike group sepsis group in which there was administration of Veronica officinalis extract showed better creatinine clearance when compared to the sepsis group, with correspondence with the histopathological analysis, in which there was a less harmful effect on the kidney tissue, prevailing only one edema parenchyma and vascular congestion.

It is known that Veronica officinalis extract promotes a reduction of pro-inflammatory chemical mediators in the lung, such as eotaxin, IL-8 and IL6 . Besides the fact of presenting an inhibitory effect on prostaglandin E2 (PGE2), derived directly from the degradation of arachidonic acid present in the cell membrane [18, 19].

In according to Rhen and Cidlowski [20], one of the main inhibitory mechanisms of inflammation is to decrease expression of the gene which codifies COX-2. COX-2 expression is initiated by the response to proinflammatory stimuli through mitogen-activated protein kinase or NF-kB inflammatory signaling pathways [21].

Although there are no studies evaluating the effects of the extract directly on the kidney, evidenced that the anti-inflammatory effects also occurred in the kidney tissue, promoting a reduction in the inflammatory response, and may even have therapeutic effect in animals subjected to sepsis, allowing improvement survival, as noted in kidney function and histopathological analysis.

Furthermore, investigations are necessary to find the possible bioactive compounds, as well as experimental studies should be conducted to confirm the efficacy of Veronica officinalis extracts in the treatment of sepsis.

\section{Conclusion}

Veronica officinalis extract caused a significant improvement of renal function and decrease the damage on kidney tissue of rats that were induced with sepsis. 


\section{Conflict of interest}

None.

\section{Financial Sources}

PIBIC-UEPA.

\section{References}

1. Martin GS. Severe sepsis and septic shock: changes in incidence, pathogens and outcomes. Expert Rev Anti Infect Ther. 2012; 10(6):701-6. doi: 10.1586/eri.12.50.

2. Araujo CV, Estato $V$, Tibiriça E, Bozza PT, Castro-Farias-Neto $H C$, Silva AR. PPAR gamma activation protects the brain against microvascular dysfunction in sepsis. Microvasc. Res. 2012; 84(2):218-21. doi: 10.1016/j.mvr.2012.05.006.

3. Machado FR, Sanches LC, Azevedo LCP, Brunialti M, Lourenço D, Noguti MA. Association between organ dysfunction and cytokine concentrations during the early phases of septic shock. Rev Bras Ter Intensiva. 2011; 23(4):426-33. doi: 10.1590/S0103$507 \times 2011000400006$.

4. Jacobs R, Honore PM, Joannes-Boyau O. Septic acute kidney injury: the culprit is inflammatory apoptosis rather than ischemic necrosis. Blood Purif. 2011; 32(1):262-5. doi: 10.1159/000330244.

5. Lerolle N, Nochy D, Guérot E, et al. Histopathology of septic shock induced acute kidney injury: apoptosis and leukocytic infiltration. Intensive Care Med. 2010; 36(1):471-8. doi: 10.1007/ s00134-009-1723-x.

6. Grundemann C, Garcia-Kaufer M, Sauer B, Stangenberg E, Konczol M, Merfort I, Zehl M, Huber R. Traditionally used Veronica officinalis inhibits proinflammatory mediators via the NF-kB signaling pathway in a human lung cell line. Journal of Ethnopharmacology. 2013; 145:118-126. doi: 10.1016/j. jep.2012.10.039.

7. Almeida LS, Gama JRV, Oliveira FA, et al. Uso de espécies da flora na comunidade rural Santo Antônio, BR-163, Amazônia Brasileira. Floresta e Ambiente. 2013; 20(4):435-46. doi: 10.4322/floram.2013.044.

8. Botelho NM, Silveira EL, Lopes LN, Santos FAF, Teixeira RKC, Silva TTd. Copaiba oil effect under different pathways in mice subjected to sepsis. Acta Cir Bras. 2014 Aug; 29(8):528-31. doi: 10.1590/S0102-86502014000800008.

9. Rusu, M. A., Tamas, M., Puica, C., Roman, I. and Sabadas, M. The hepatoprotective action of ten herbal extracts in CCl4 intoxicated liver. Phytother. Res. 2005; 19: 744-749. doi: 10.1002/ptr.1625

10. Coca SG, Yusuf B, Shlipak MG, Garg AX, Parikh CR. Long-term risk of mortality and other adverse outcomes after acute kidney injury: a systematic review and meta-analysis. Am J Kidney Dis. 2009; 53(6):961-73. doi: 10.1053/j.ajkd.2008.11.034.

11. Doi K, Leelahavanichkul A, Yuen PST, Star RA. Animal models of sepsis and sepsis-induced kidney injury. J Clin Invest. 2009; 119(10):2868-78. doi: 10.1172/JCI39421.

12. Walker PD, Shah SV. Reactive oxygen metabolites in endotoxininduced acute renal failure in rats. Kidney Int. 1990; 38(6):112532. doi: 10.1038/ki.1990.322.
13. Padilha KG, Sousa RMC, Silva MCM, Rodrigues AS. Patient's organ dysfunction in the Intensive Care Unit according to the Logistic Organ Dysfunction System. Rev Esc Enferm USP [Internet]. 2009 [cited 2011 Nov 11]; 43(spe 2):1205-5. doi: 10.1590/S0080-62342009000600018.

14. Uchino S, Kellum JA, Bellomo R, Doig GS, Morimatsu H, Morgera $S$, et al. Acute renal failure in critical ill patients: a multinational, multicenter study. JAMA. 2005; 294(7):813-8. doi: 10.1001/ jama.294.7.813.

15. Bellomo R, Ronco C, Kellum JA, Mentha RL, Palevsky P. Acute renal failure-definition, outcomes measures, animal models, fluid therapy and information technology needs: the Second International Consensus Conference of the Acute Dialysis Quality Initiative (ADQI) Group. Crit Care. 2004; 8(4):R204-12. doi: $10.1186 /$ cc2872.

16. Mentha RL, Kellum JA, Shah SV, Molitoris BA, Ronco C, Warnock $D G$, et al. Acute Kidney Injury network: report of an initiative to improve outcomes in acute kidney injury. Crit Care. 2007; 11(2):R31. doi: 10.1186/cc5713.

17. Pinto CF, Watanabe $M$, Fonseca CD, Ogata Cl, Vattimo MFF. A sepse como causa de lesão renal aguda: modelo experimental. Rev. esc. enferm. USP. 2012; 46(spe). doi: 10.1590/S008062342012000700013.

18. Sastre B, Del P.V. Role of PGE2 in asthma and nonasthmatic eosinophilic bronchitis. Mediators of Inflammation. 2012, 645383. doi:10.1155/2012/645383.

19. Scholz S, Williamson $\mathrm{G}$. Interactions affecting the bioavailability of dietary polyphenols in vivo. International Journal for Vitamin and Nutrition. 2007: 77, 224-235. doi: 10.1024/03009831.77.3.224.

20. Rhen T, Cidlowski JA. Anti-inflammatory action of glucocorticoids - new mechanisms for old drugs. New England Journal of Medicine. 2005: 353, 1711-1723. doi: 10.1056/NEJMra050541.

21. Viljoen A, Mncwangi N, Vermaak I. Anti-inflammatory iridoids of botanical origin. Current Medicinal Chemistry. 2012: 19, 2104-2127. doi: 10.2174/092986712800229005

Publish in International Archives of Medicine

International Archives of Medicine is an open access journal publishing articles encompassing all aspects of medical science and clinical practice. IAM is considered a megajournal with independent sections on all areas of medicine. IAM is a really international journal with authors and board members from all around the world. The journal is widely indexed and classified Q2 in category Medicine. 